BULLETIN Bulletin hispanique

HISPANIQUE Université Michel de Montaigne Bordeaux

113-1| 2011

Actes de 2 colloques

\title{
«Trocar el libro por la baraja»
}

eutrapelia y poemario impreso

Ignacio García Aguilar

\section{(2) OpenEdition}

Journals

Edición electrónica

URL: http://journals.openedition.org/bulletinhispanique/1326

DOI: 10.4000/bulletinhispanique.1326

ISSN: 1775-3821

Editor

Presses universitaires de Bordeaux

Edición impresa

Fecha de publicación: 1 junio 2011

Paginación: 103-128

ISBN: $978-2-86781-740-3$

ISSN: 0007-4640

Referencia electrónica

Ignacio García Aguilar, « «Trocar el libro por la baraja» », Bulletin hispanique [En línea], 113-1 | 2011,

Publicado el 01 junio 2014, consultado el 01 mayo 2019. URL : http://journals.openedition.org/

bulletinhispanique/1326 ; DOI : 10.4000/bulletinhispanique.1326 


\title{
«Trocar el libro por la baraja»: eutrapelia y poemario impreso $^{1}$
}

\author{
Ignacio García Aguilar \\ Universidad de Huelva - España
}

L'Entretemiento de las musas, baraja nueva de Francisco de la Torre y Sevil, imprimé à Saragosse en 1654, est une nouveauté éditoriale conçue dans le contexte de la poésie aragonaise. Il met en cuvre une dispositio ludique, afin d'associer la poésie savante imprimée à des jeux littéraires et académiques et à des pratiques liées au marché des loisirs de masse à travers l'image $d u$ livre-jeu de cartes.

El Entretenimiento de las musas, baraja nueva de Francisco de la Torre y Sevil, impreso en Zaragoza en 1654, es una innovadora propuesta editorial concebida en el contexto poético aragonés, que utiliza una dispositio lúdica para vincular la poesía culta impresa con juegos literarios y académicos, pero también con prácticas concernientes al mercado del ocio masivo a través de la imagen del libro-baraja.

The Entretenimiento de las musas, baraja nueva by Francisco de la Torre y Sevil, printed in Zaragoza in 1654, is an innovative publishing proposal, conceived in the poetic context of Aragon which uses a recreational dispositio to link cultivated printed poetry with literary and academic games, but also with practices concerning the mass entertainment market through the image of the book-deck of cards.

Mots-clés : Torre y Sevil - Poésie imprimée - Poésie aragonaise - Livre-jeu de cartes.

1. Este trabajo se ha realizado al amparo del Programa Juan de la Cierva del Ministerio de Ciencia e Innovación (JCI-2007-36-509) y en el marco del proyecto Arias Montano: Teología y Humanismo (FFI2009-07731).

Bulletin Hispanique, Tome 113, n 1 - juin 2011 - p. 103 à 128. 
En La cueva de la nada, crisi octava de la tercera parte de El Criticón (1657), dibuja Gracián a una serie de sujetos que esquivan premeditadamente el esfuerzo y por ello «se sepultan en vida y se vienen por su pie a enterrar en los sepulcros del ocio, en las urnas de la flojedad, quedando cubiertos del polvo del eterno olvido» ${ }^{2}$. Ante los ojos de Critilo y Andrenio desfilan distintos tipos humanos abocados sin remedio a la nada. Pero de entre todos ellos destaca, excepcionalmente, un mozo que es enviado por su padre a la Universidad de Salamanca "para que por el atajo de las letras [...] llegase a conseguir un gran puesto» ${ }^{3}$. Muy pronto abandona las aulas y se dedica al ocio y los divertimentos, momento en que el personaje del Honroso, apenado por la situación, le reprende y le aconseja que vuelva al camino del estudio, lo que provoca un cambio inmediato en la actitud del mozo, quien finalmente consigue una presidencia, «honrando» de ese modo "su casa y su patria». Pero consciente de la excepcionalidad del suceso, el narrador de esta alegoría moral asevera: "Pero fue este la fénix entre muchos patos, que lo común es trocar el libro por la baraja, el teatro literario por el cómico corral, y el vade por la guitarra ${ }^{4}$.

La contraposición entre estas dos ternas de elementos, "libro-teatro literario-vade», por un lado, y «baraja-cómico corral-guitarra», por otro, bien pudiera servir para ilustrar los dos polos opuestos en torno a los cuales se desarrolla la cultura del ocio en la época: la de naturaleza privativa y minoritaria de las élites intelectuales y la cultura mayoritariamente dirigida y urbana de las clases populares. Pero esta reflexión, por obvia y conocida, no aporta novedad alguna.

Más interés podría despertar, a la luz de este fragmento, que el autor del mismo, Baltasar Gracián, redactase y publicara, apenas tres años antes de que se imprimiera la tercera parte de El Criticón (1657), la aprobación al Entretenimiento de las musas [...] baraja nueva de versos dividida en cuatro manjares (1654), volumen firmado por Feniso de la Torre, seudónimo bajo el que se esconde Francisco de la Torre y Sevil 5 . Tal interés radicaría en que

2. Baltasar Gracián, El Criticón, ed. Emilio Hidalgo Serna y Elena Cantarino, Madrid, Espasa Calpe, 2002, p. 733.

3.Ibid., p. 738.

4. Ibid.

5. Para los datos sobre de la Torre y Sevil vid. la introducción de Manuel Alvar a su Edición y estudio del Entretenimiento de las musas de don Francisco de la Torre y Sevil, Valencia, Universidad, 1987, pp. 3-73; y más recientemente el trabajo de Enric Querol Coll, Estudis sobre cultura literària a Tortosa a l'edat moderna, Barcelona, Publicacions de l'Abadia de Montserrat, 
el poemario aprobado por Gracián se sustenta, justamente, en virtud del denostado "trueque» entre "libro" y «baraja»-con todas las irrigaciones conceptuales y literarias que esto permite generar.

En su aprobación al Entretenimiento alaba Gracián el volumen de un modo generoso ${ }^{6}$, y no sólo valida legalmente el producto impreso, sino que anticipa, sin saberlo, el título de lo que antologaría Francisco de la Torre y Sevil veinticinco años después: las Delicias de Apolo. Recreaciones del Parnaso (1670). El libro sería impreso por José Alfay ${ }^{7}$, el mismo que había publicado apenas un mes antes que el Entretenimiento de las musas -si atendemos a las fechas de las aprobaciones y las licencias ${ }^{8}$ las Poesias varias (1654), en donde parece que también intervino la mano de Gracián, de acuerdo con la carta que le dirige el Marqués de San Felices, de la que se puede deducir que el jesuita participó activamente en la antología' ${ }^{9}$ Con la impresión de las Delicias de Apolo en 1670 cumpliría Alfay, además, la promesa lanzada en el

2006, en especial el capítulo 8 Francesc de la Torre: un ingeni barroc entre quatre regnes, pp. 247-284, en donde además de valiosos datos sobre la vida, obra y contexto sociocultural del poeta se incluye un anexo final con una rigurosa recopilación de la importante producción literaria que produjo Torre y Sevil en certámenes, justas o preliminares de libros, entre otros.

6. Afirma Gracián haber «leído este libro, que se inscribe Entretenimiento de las musas y, pudiera ańadir, delicias de Apolo, recreaciones del parnaso, y los buenos ratos del gusto y del ingenio. Confieso que tenía estos días postrado el apetito de un grato hartazgo de coplas; pero luego que comenzó a cebarse en los manjares desta nueva baraja de versos, tan llenos de sales, donaires, agudezas y concetos [...]» (Manuel Alvar, op. cit., p. 79. Modernizamos la grafía en este texto y en las referencias subsiguientes a esta edición). Sobre esta aprobación vid. Aurora Egido, "Cuatro aprobaciones y una dedicatoria de Baltasar Gracián», en Pierre Civil (dir.), Siglos dorados. Homenaje a Augustin Redondo, Madrid, Castalia, 2004, t. I, pp. 385-398. Para el valor institucional de las aprobaciones en el siglo XVII vid. Ignacio García Aguilar, "De Trento al Parnaso II: aprobación textual y sanción poética en los poemarios impresos del siglo XVII», en Begoña López Bueno (dir.), El canon poético en el siglo XVII, Sevilla, UniversidadGrupo PASO, 2010, pp. 241-267.

7. Para el valor institucionalizador del poemario vid. Pedro Ruiz Pérez, «Entre dos parnasos: poesía, institución y canon», Criticón, no 103-104, 2008, pp. 207-231. Dadson señaló los vínculos entre el título del volumen de 1670 y la apreciación vertida por Gracián en la aprobación del Entretenimiento (1654), y reparó también en el hecho de que el prólogo de las Delicias de Apolo (1670) es el mismo de las Poesías varias (1654), a excepción del final, en el que confiesa Sevil que «lo hize por dar gusto a un Librero amigo» (cf. Trevor Dadson, «Dos autógrafos desconocidos de Gabriel Bocángel», El Crotalón, no 2, 1985, pp. 275-298).

8. La licencia de las Poesías varias se concede el 6 de junio de 1654. Sólo unas semanas más tarde, el 13 de julio, se da licencia de impresión para el Entretenimiento de las musas.

9. Vid. la edición de José Manuel Blecua de las Poesías varias de grandes ingenios españoles recogidas por Josef Alfay, Zaragoza, Institución Fernando el Católico, 1946, pág. x, así como también Adolphe Coster, Baltasar Gracián, Zaragoza, Institución Fernando el Católico, 1947, Apéndice I, nº 29. 
prólogo a sus Poesías varias de sacar un segundo producto editorial análogo en caso de funcionar el primero ${ }^{10}$.

Y no debe obviarse, al hilo de estas referencias, que el volumen de las Poesías varias está dedicado, precisamente, a Francisco de la Torre y Sevil, el poeta más joven y descollante de este entorno aragonés ${ }^{11}$; quien por cierto aún no había ofrecido nada hasta ese momento (junio de 1654) a las letras de molde, a excepción de los siete poemas que incluye el propio Alfay en su antología colectiva ${ }^{12}$ y que, salvo un soneto dedicado $A$ la Magdalena, no aparecieron en la antología individual publicada un mes más tarde por Torre y Sevil.

Que en la aprobación de Gracián al Entretenimiento se esgrima la autoridad de Horacio y Marcial y se defina a De la Torre como «ingenioso y discreto» ${ }^{13}$ delata, fundamentalmente, los principios de una estética compartida. Pero además, el signo barroco del «ingenio» permite vincular al joven poeta con el rótulo intitulador de la antología impresa por Alfay, también en Zaragoza, el mes anterior. Esto es, con las referidas Poesias varias de grandes ingenios, título sumamente significativo, pues no se trata ya de «ilustres poetas» ni tampoco «flores» -al modo de las Fiori renacentistas italianas, cuyo descendiente peninsular más semejante eran las de Espinosa ${ }^{14}-$, sino de la agrupación de una rica varietas que atañe a las dimensiones de la inventio poética, la dispositio

10. «De todo te ofrezco, con que no puedo dejar de acertar en algo, y si fuere a tu gusto, habré acertado en todo, prometiéndote sacar a luz más numeroso volumen mi agradecimiento» (op. cit., p. 5).

11. José Alfay ubica, antes del Prólogo al lector, su dedicatoria $A$ don Francisco de la Torre, caballero del hábito de Calatrava. En el texto alude a las convencionalidades de este género apologético, pero las subvierte en cierto modo al evitar exponer la genealogía y los méritos del dedicatario: "Róbole a esta dedicatoria lo que a todas hace grandes, que es delinear la ilustre ascendencia del Mecenas, pero porque ésta no pase a grandísima, callo la de v. m., pues por muy conocida, fuera osadía de mi poquedad atreverme a su narración» (ibid., p. 4).

12. Son los que comienzan «Refieren muy resolutos», «Difunta al gusto, viva ya a la pena», «Rompe la concha de esmeraldas», "Deme el discreto razón», "Cayó Inés, y yo no niego», "Al ver tu hocico extendido" y "Con polvos Lisis se pinta» (op. cit., pp. 17, 75, 102, 125, 193, 194 y 198).

13. «[...] de tal modo fue entrando en comer que queda picado para otras muchas obras su ingenioso autor Don Francisco de la Torre, en quien no es novedad sino hábito lo ingenioso y lo discreto. Su torre le llama Helicona, que cuando más rimas hace, no cae, no descaece, antes se empina a herir los astros con sublime dorado chapitel: Sublimi feriam sydera vertice. Por ellas bebe los rosicleres del día, et prius arcano satiatur lumine Phoebi, y, bañada de los brillantes rayos del laureado planeta, bien se merece salir a la luz de la estampa [...]» (op. cit., p. 79).

14. Sobre esto vid. Blecua, op. cit., p. xi. 
editorial y, por supuesto, a la de un conjunto de auctoritates contemporáneas regidas por el principio del ingenio.

Y de hecho, y acaso no por casualidad, en lo que respecta al ingenio, el mismo Alfay se había referido en la dedicatoria a Sevil de las Poesías varias en términos similares a los empleados por Gracián semanas más tarde en su aprobación al volumen del Entretenimiento. La diferencia más sustantiva entre ambos textos estriba en que el librero impresor se expresa de modo más explícito que el jesuita, al vincular la recepción del poemario con las esferas de un entretenimiento lúdico y jocoso, pero no masivo, sino diferenciado en virtud del entendimiento. Conforme a esto, afirma Alfay, a propósito de las Poesías varias, que las sacaba «a la común luz para ingenioso entretenimiento de entendidos» ${ }^{15}$.

Sigue a esta dedicatoria el Prólogo al lector, también escrito por Alfay, que se inicia exactamente del mismo modo: con una confesión clara de intenciones, afirmando entonces que "varias son las poesías que te ofrezco, Lector amigo, pero el deseo de entretenerte con ellas es único» ${ }^{16}$. Sólo unas líneas más adelante, el "entretenimiento» vinculado a la poesía culta y a la varietas se formula en este prólogo de un modo que recuerda a una de las varias anfibologías que conforman el título y buena parte del diseño conceptual del Entretenimiento de Sevil. Conforme a ello, cuando justifica Alfay la variedad de las composiciones escogidas -algunas de ellas «muy vulgares», según reconoce el propio prologuista- se ampara en el gusto vario apelando al universo heterogéneo de los alimentos. Reconoce entonces que las poesías «no son todas iguales, porque no son iguales todos los lectores; no son unos los alimentos, porque son varios los estómagos» ${ }^{17}$.

Se puede decir a este respecto que tampoco eran unos los «alimentos» de la Baraja, pues hasta cuatro manjares conformaban el poemario de Sevil; ya que si bien es cierto que el término «manjar» remite, en el contexto naipesco, a los distintos palos de la baraja, a nadie se le oculta su sentido culinario o alimenticio. $\mathrm{Y}$ mucho menos a quienes se valieron de los preliminares para elogiar al Entretenimiento y a su autor. Así, por ejemplo, Ana Abarca de Bolea -autora de una baraja a lo divino ${ }^{18}$ - refiere en su soneto preliminar que «en el Parnaso guisados / con manjares sazonados / hacéis dar a esta flor fruto» ${ }^{19}$. Y en sentido análogo, se refiere Juan de Moncayo a

15. Op. cit., p. 4. La cursiva es nuestra.

16. Ibid., p. 5. La cursiva es nuestra.

17.Ibid., p. 5.

18. Cf. Manuel Alvar, Estudio sobre el «Octavario» de doña Ana Abarca, Zaragoza, Institución Fernando el Católico, 1945, p. 58.

19. Op. cit., p. 83. 
los «manjares sazonados» en su elogio en prosa; y añade posteriormente, al explicar el significado simbólico de los distintos elementos que conformaban el poemario, que eran «los manjares pasto del alma» ${ }^{20}$.

Las concomitancias referidas hasta el momento, así como las presencias reiteradas de unos y otros en las Poesías varias y en el Entretenimiento de las musas, permiten presuponer que la terna compuesta por Alfay, Torre y Sevil y Gracián no sería ajena a la confección de ambos productos: el uno, antología individual de autor único -realizada en vida como ejemplo de una obra no acabada - y conformada en virtud de patrones temático-naipescos que determinaban la estructura dispositiva de una importante variedad de composiciones; el otro, antología colectiva de poetas -pasados, pero también presentes, el propio Sevil entre ellos- que se ahormaban en tonos y modelos genéricos variados.

Además, la dedicatoria de las Poesías varias dirigida a Sevil induce a pensar que el joven poeta y Alfay mantuvieron una relación estrecha durante el proceso de fabricación de ambos libros. Pero más allá de esto, interesa reparar en que el criterio que rige la selección de los poemas para cada volumen parece delatar ciertos puntos de conexión en lo relativo a la novedad de lo publicado y al engarce de cada composición con respecto a la dispositio general de uno y otro impreso.

\section{DEL POEMA EXENTO A LA BARAJA POÉTICA: FUNCIÓN Y SENTIDO DE LA DISPOSITIO LÚDICA}

Esta hipótesis se refuerza con el análisis comparativo de algunos de los poemas de Torre y Sevil que fueron seleccionados para ser ubicados en las Poesias varias o en el Entretenimiento, pero que bien podrían haberse permutado o incluso haber funcionado con mayor efectividad publicándose en ambos volúmenes -aunque en ese caso se habría restado algo de la novedad anunciada en los preliminares ${ }^{21}$.

Así, y espigando algunos textos, resulta llamativo, por ejemplo, que el poema de Torre y Sevil $A$ una boca grande de una mujer (que recoge

20. El texto en prosa aparece titulado como Elogio a don Francisco de la Torre, caballero del hábito de Calatrava, autor destas rimas, disimulado con el nombre de Feniso. Introducción para el que leyere, por don Juan de Moncayo, marqués de San Felices (op. cit., pp. 87-88).

21. Además de lo anunciado en el título del volumen y en las composiciones elogiosas que adornan los preliminares, el extenso poema en redondillas de Torre y Sevil Al lector redunda justamente en estas nociones de novedad (op. cit., pp. 92-95). 
Alfay) ${ }^{22}$ pudiese encajar, temáticamente y de acuerdo con la estructura general del Entretenimiento, mucho mejor en la Baraja que, pongamos por caso, el dirigido $A$ un pie grandísimo, el cual se dispone justo después del dedicado $A$ una niña alcanzada por medio de una vieja y después no proseguida por el mal aliento de su boca ${ }^{23}$. Y una concomitancia similar -pero no por la atención dedicada a la «boca», sino por la referencia al tema de la mujer aprovechada-, se podría decir de la copla impresa por Alfay $A$ una dama muy interesada, habiéndola visto tropezar ${ }^{24}$, que está dirigida a Inés. Dicha copla podría haber entablado en el Entretenimiento una relación cotextual muy efectiva con respecto al poema dirigido $A$ Nise [parónimo de Inés] que despreciaba su galán por feo ${ }^{25}$-también interesada, por tanto-, composición que antecede a las redondillas a Una señora que siendo muy blanca tenía sobre los labios una peca negra ${ }^{26}$. La tal señora, por cierto, se llamaba Inés. Las conexiones entre estos tres poemas habrían permitido su inclusión perfectamente en el poemario de Torre y Sevil, pero se habría roto entonces la estructura de pares, o de pregunta y respuesta, que caracteriza, como veremos, la dispositio del Entretenimiento.

Ocurre algo semejante con el poema $A$ una dama fea y negra que se pintaba, recogido en Alfay ${ }^{27}$, el cual podría disponerse de modo muy efectivo junto con el dirigido $A$ un retrato de una señora hermosisima, [que] no obstante le faltaba un ojo ${ }^{28}$, y sustituiría entonces a las quintillas Pidiendo la mano a $F_{i l i}{ }^{29}$. Y consideraciones similares podrían ser válidas para el Soneto a la rosa $^{30}$ si se compara con los sonetos dirigidos $A$ una mariposa ${ }^{31}$ y $A$ una vela ardiendo $^{32}$.

Estas hipótesis, así expuestas, podrían fácilmente interpretarse como resultado de un capricho propio o de especulaciones sin fundamento y, sobre todo, sin utilidad crítica. Pero si nos aventuramos a formularlas es porque pensamos que existe en el diseńo dispositivo del Entretenimiento un afán por estructurar pequeñas series con homogeneidad temática y variedad estrófica; y que en la elección de unas u otras composiciones fue

22. Op. cit., p. 194.

23. Op. cit., pp. 217-218.

24. Op. cit., p. 193.

25. Op. cit., p. 202.

26. Ibid., pp. 203-204.

27. Op. cit., p. 198.

28. Op. cit., p. 199.

29. Ibid., pp. 200-201.

30. Op. cit., p. 102.

31. Op. cit., p. 177.

32.Ibid., p. 151. 
muy determinante, y esto es obvio, el modelo macroestructural de baraja, con la asignación simbólico-temática de los distintos palos o manjares; pero no fue menos importante la voluntad de preservar el concepto de «nuevo» «entretenimiento» que aparecía en la portada del libro.

El detenido cuidado por la selección y por la posterior disposición de los materiales poéticos delatan el gran interés que puso Sevil tanto en la novedad de los poemas impresos como en el novedoso diseńo macroestructural de la baraja nueva de versos que resulta ser su poemario. Ocurre que la especial disposición del volumen -en dípticos poemáticos o series de composiciones duales- tiene implicaciones que van más allá de la mera estructura naipesca, pues con el producto editorial de Sevil se alcanza una conceptualización lúdica que rebasa la simple organización temática de composiciones religiosas (oros), heroicas (espadas), líricas (copas) y burlescas (bastos) ${ }^{33}$.

Así, y como si de un juego de provocaciones se tratase, los poemas intentarían reproducir en su disposición una cierta mecánica de envío y respuesta, a la manera, por ejemplo, de juegos y prácticas poéticas cortesanas bien conocidas y ya concretadas editorialmente en el Libro de motes de damas $y$ caballeros (1535) de Luis de Milán ${ }^{34}$-impreso en $16^{\circ}$, justo el tamaño de una baraja de cartas-; o al modo también de actividades de academia, espacio idóneo de experimentación en donde la concepción lúdica de la literatura es evidente y elementos como la utilización de seudónimos, las pruebas de ingenio y habilidad o los juegos de provocación y contestación articulan el funcionamiento y desarrollo de buena parte de las sesiones.

Pero en el caso del Entretenimiento la metáfora naipesca aporta una inédita originalidad, pues más allá del juego entre roles ficcionales asignados a personas concretas, son los poemas, desde su propia autonomía formal y temática, los que se solicitan y completan; en fin, se arrastran y se asisten como en los juegos de bazas, pero no ya únicamente desde la perspectiva de los palos o manjares de la baraja, sino fundamentalmente desde la inventio y las normas de los tópicos literarios conocidos.

Tal modelo de estructuración o dispositio lúdica funcionaría desde el comienzo mismo del libro. Así, en los dos poemas iniciales del Manjar primero parece claro que el dedicado Al oro induce a la ubicación correlativa del siguiente, la denominada Invocación a Dios, introduciéndose en el

33. Manjar primero servido en el oro de sacros asuntos (op. cit., pp. 104-136); Manjar segundo servido en las espadas de heroicos asuntos (ibid., pp. 137-172); Manjar tercero servido en las copas de líricos asuntos (ibid., pp. 173-205) y Manjar quarto servido en los bastos de burlescos asuntos (ibid., pp. 206-244).

34. Luis de Milán, Libro de motes de damas y caballeros (Valencia, Francisco Díaz Romano, 1535), ed. facsímil, Valencia, Librería París-Valencia, 1982. 
oro de lo sacro, cuyo anfibológico verso conclusivo es muy clarificador al respecto: «en vos oro lo que oro» ${ }^{35}$. Este juego de diálogos interpoemáticos articulados en series de dos se continúa en el díptico siguiente, de modo que el soneto ocasional En consideración de haber bajado la Virgen Nuestra Señora, acompañada de los santos Pedro y Pablo, quando dio, a la Iglesia de la ciudad de Tortosa, la preciosa cinta suya de red que hoy se venera en ella tiene su correlato en la décima siguiente, de tema y, sobre todo, designación paratextual muy acorde a la estructura indicada: En aplauso de la misma preciosa cinta, mirando la red ${ }^{36}$. Se prosigue con los pares de poemas a cuatro mártires femeninos y masculinos: Santa Magdalena y Santa Lucía ${ }^{37}$, por un lado, y San Bartolomé y San Sebastián, por otro ${ }^{38}$. La simetría del par siguiente no es tan perfecta o perceptible como en los casos anteriores, pues el soneto $A$ San Pedro en el llanto de su conversión es seguido de una décima al Lamento de un pecador endurecido. Pese a que el sujeto del segundo poema varía bastante con respecto al primero, la doble mención a la «piedra» (étimo común) en la décima, así como las concomitancias entre la simbología del agua en la conclusión del soneto a Pedro ${ }^{39}$ y en la décima ${ }^{40}$ conforman un díptico, más conceptual en este caso, que encaja bastante bien dentro de la referida dispositio lúdica de provocación y respuesta. Bastante más explícito es el seguimiento a la estructura de pares en la siguiente serie, en donde el soneto A San Gerónimo está acompañado de unas décimas $A$ lo mismo ${ }^{41}$. Y tras éstas se disponen dos sonetos a la muerte de Cristo y a la de la Virgen ${ }^{42}$, así como una canción $A$ la Virgen en el misterio de su Purísima Concepción y una octava A la gloriosa Virgen en el regocijo de su Coronación ${ }^{43}$. Siguen a estos poemas unas quintillas de ciego a la Vida y muerte de San Lamberto y un romance a San Juan Bautista, y tras ellos una silva de consonantes $A$ San Francisco en la impresión de las llagas y un romance $A$ Cristo en el paso de ascenderle en la

35. Op. cit., pp. 104-105.

36. Ibid., pp. 106-107. El resaltado es nuestro.

37. A Santa Magdalena en su gloriosa conversión y A Santa Lucía en la pérdida de sus ojos (ibid., pp. 108-109).

38. A San Bartolomé en su martirio y A San Sebastián y a sus flechas (ibid., pp. 110-111).

39. «Yo al revés, del engaño entre la yedra, / soy con blanda lascivia y pecho duro / torrente al cometer y al llorar piedra» (ibid., p. 112, vv. 12-14).

40. «Oh, humana piedra, llorad. / Haréis, si así el agua os medra, / al ser lluvia lo que es piedra, / riego lo que es tempestad» (ibid., p. 113, vv. 7-10).

41. Ibid., pp. 114-115.

42. «Funestos señales en la muerte de Christo y $A$ la Virgen en su gloriosa muerte» (ibid., pp. 116-117).

43. Ibid., pp. 118-121. 
Cruz, además de dos poemas de circunstancias ${ }^{44}$. El manjar se concluye con un Romance en esdrújulos al Santísimo Sacramento y otro Al mismo asunto ${ }^{45}$.

Un criterio dispositivo idéntico guía la organización poemática en los otros manjares desde el comienzo de las series. Conforme a ello, en el Manjar segundo el poema $A$ la valerosa espada de Carlos Quinto en ocasión de haberse trasladado las cenizas deste invicto emperador al panteón nuevo es respondido por el soneto $A$ la espada ${ }^{46}$. Y en el siguiente manjar la silva titulada Conformidad del vino y del amor sin repetir concepto de los que al mismo asunto dixo Virgilio en los versos de Nec Veneris, nec tu vini, etc. es respondida por el soneto titulado Difinición de Amor ${ }^{47}$.

Resultaría muy prolijo analizar uno por uno todos estos juegos de pares ${ }^{48}$, pues no en todas las ocasiones siguen un equilibrio tan perfecto o evidente; pero pensamos que existe, sin duda, una estructura dual subyacente -a la manera de los juegos de provocación y respuesta ya mencionados- que rige la ordenación de los poemas en los cuatro manjares de esta baraja. Una muestra muy palpable de este celo por el diseño dispositivo del libro se puede ver de manera más convincente al cotejar dos estados distintos del Entretenimiento de las musas.

Conviene recordar en este punto que cuando el maestro Alvar editó el Entretenimiento en 1987 transcribió el soneto que aparece en la página 127 de la mayoría de los ejemplares conocidos ${ }^{49}$. Tres años después, sin embargo, publicó una breve nota para dar cuenta de la referencia que le facilitó un amigo bibliógrafo zaragozano ${ }^{50}$. En ésta, se mencionaba un ejemplar en cuya

44. Al haber caído el año de 1644 en un mesmo día la Encarnación y muerte de Cristo y también por el mismo tiempo la creación del mundo, según la opinión más común de los astrólogos y En consideración de haber llorado mucho una señora el rato que entraba a ser religiosa, quedando después gustosisima de tan dichoso estado (ibid., pp. 132-133).

45. Ibid., pp. 134-136.

46. Ibid., pp. 137-139.

47. Ibid., pp. 173-175.

48. Esta cuestión será objeto de un análisis más detallado en un trabajo futuro.

49. Op. cit., p. 210.

50. «Después de editado el Entretenimiento de las musas he consultado otro ejemplar del año 1654, que difiere de los tres que ya conocía (el de la Biblioteca Nacional de Madrid y los de las Bibliotecas Universitarias de Zaragoza y de Valencia). A la gentileza de don Alfonso Fernández, bibliófilo zaragozano, debo el poder presentar la discrepancia, pues coincidiendo todos los ejemplares en los textos incluidos, el que ahora comento difiere en un punto. En la página 117 [sic] se ha sustituido el texto que yo imprimo y se ha incluido este: [...]» (Manuel Alvar, "Dos notas sobre don Francisco de la Torre y Sevil», en Víctor García de la Concha et alii (ed.), Teatro del Siglo de Oro. Homenaje a Alberto Navarro González, Kassel, Edition Reichenberger, 1989, pp. 1-4, p. 1). Nosotros utilizaremos para nuestro análisis el ejemplar del Entretenimiento conservado en la Biblioteca de la Universidad Complutense de Madrid 
página 127 figuraba un soneto distinto del editado en 1987, y declaraba Alvar no entender por qué se había eliminado una composición que, a su juicio, era de grandísima calidad ${ }^{51}$. Pensamos que tal vez las consideraciones propuestas en relación a la dispositio lúdica puedan servir para entender mejor la permutación de un soneto por otro en los dos estados del Entretenimiento.

Justo al inicio del manjar cuarto -el servido en los bastos de burlescos asuntos-, y tras la silva de consonantes ${ }^{52}$ que tiene como motivo el Báculo de la vieja Celestina colgado en el templo de la diosa Venus, se sitúa una serie de seis poemas fuertemente trabados entre si $^{53}$, en donde se produce el cambio advertido por Alvar ${ }^{54}$.

Así pues, tras la referencia burlesca al modelo literario celestinesco sigue otra burla, también literaria, que consiste en la desacralización de los paradigmas de Beatriz ${ }^{55}$ y Laura ${ }^{56}$, sujetos femeninos canónicos de la

con signatura BH FLL 229561, que también pertenece al mismo estado de impresión que el citado por Alvar.

51. «No acierto a saber las causas del cambio, pues el soneto que imprimí, con su marcado sesgo quevedesco, era una excelente muestra del género satírico [...] ¿Acaso la Fábula pertenece a una corrección del libro hecha ya en pruebas? Queda, pues, el soneto que ahora reproduzco como un poema que hubiese sido "desconocido" de no haber mediado la casual aparición» (ibid., p. 2).

52. Todos los palos de esta baraja se abren con una silva de consonantes a la que siguen series de sonetos y décimas articuladas del mismo modo en las cuatro secciones de que consta el poemario.

53. Se trata de tres series duales de poemas: el soneto De una muger que, estando preñada, publicaba ser doncella cubriendo el achaque con nombre de opilación y la décima $A$ Laura que, no ocultando el entretenimiento, se quejaba de la murmuración; el soneto Descripción de un amigo de un viejo de mala cara y peor mujer y la décima $A$ una mujer, insigne música, que, pensando lograr mucho interés de haberla oído cantar un mercader rico y avaro, se quedó burlada, ambos destinados a un recipiendario poético denominado Fabio; por último, el soneto $A$ una vieja afeitada y la décima $A$ la misma imaginándola pelota, dirigidos a Clori (op. cit., pp. 208213).

54. Se trata de la sustitución del soneto Fábula entendida con nueva moralidad por el que lleva por título Descripción de un amigo de un viejo de mala cara y peor mujer.

55. «Esta nińa bellaca, o acá bella, / en quien tanto picado amante pica, / está empachada, porque desde chica / no pudo digerir el ser doncella. / Que no conoce hombre, dice ella, / mas como a cuantos ve su amor publica, / que sólo no ha llegado, se replica, / el que no la conoce a conocella. / Hipócrita su talle al abultalle / contando en ocho faltas mil excesos, / de sus anchuras se ha vestido el talle. / Oye de ti, parlera, tus progresos, / ¿qué importa que en la boca la voz calle / si en el vientre, oh Beatriz, te hablan los huesos?» (ibid., p. 208).

56. "Libre Laura se descoca / y quiere en lo mudo experta / abriendo a todos la puerta, / que todos cierren la boca. / Otro es cuanto le toca / y otro nombre intenta dalle: / deudo, el galán al entralle; / la visita, cortesía; / topo el lince; sombra el día, / y sólo la calle, calle» (ibid., p. 209). 
lírica italiana, y en el avejentamiento prostibulario de Clori ${ }^{57}$. Clori es bien conocida por sus escarceos mitológicos con Céfiro y por ser destinataria prototípica de numerosísimos poemas durante el Siglo de Oro, hasta el punto de que en El curioso impertinente, por ejemplo, Anselmo refiere a Camila que «Lotario andaba enamorado de una doncella principal de la ciudad, a quien él celebraba debajo del nombre de Clori» ${ }^{58}$. Y ya Lope, en su Burguillos, había ridiculizado a Clori para trazar el antirretrato de la dama ideal renacentista, en su soneto $A$ una dama roma y fría. Pero es que aparte de las referencias literarias, Clori es también en la mitología el sobrenombre que adopta Melibea (la hija de Anfión y Níobe) por la palidez extrema que le produjo presenciar el asesinato de sus hermanos a manos de Apolo y Artemisa, lo que permite establecer también una conexión con la silva de consonantes inicial dirigida a Celestina.

Celestina, Beatriz, Laura y Clori sirven para ajustar de modo óptimo esta suerte de anticanon burlesco con que se inicia la última sección de la baraja. Por ello, la inclusión de Fabio como sujeto de advertencias resulta muy oportuna, pues tratándose de un protagonista masculino actúa como idóneo contrapunto inventivo y dispositivo con respecto a los otros poemas, ya que puestos a buscar un sujeto-poético masculino ninguno mejor que el proveniente del "linaje de Fabio» ${ }^{59}$, acaso el más popular del Siglo de Oro.

De acuerdo con estos presupuestos se podría justificar y entender entonces la modificación que se produjo en la imprenta, ya que permutando el soneto del primer estado del libro, Fábula entendida con nueva moralidad-el cual entroncaría con los sonetos precedentes mediante el tema de las dos mujeres: la vieja y la moza ${ }^{60}$-, por la Descripción de un amigo de un viejo de mala cara y peor mujer -que tiene como protagonista a Fabio, igual que la décima

57. «No cual otras con labio enfurecido, / porfiada Clori, en el vivir perenne, / muestra los dientes, porque no los tiene, / ni peina canas, porque le han caído. / Vaso de solimán el deslucido / rostro y, en las arrugas que contiene, / lo que gastó el veneno a pagar viene, / sin haberlo comido ni bebido. / ¡Oh, tú!, legisladora que a tu vida / a tu edad le fulminas un proceso / ilustrando a Vegecio no entendida. / Deja del unto el achacoso exceso, / porque, siendo tu carne huida, / será cualquier afeite sobre hueso» (ibid., p. 212).

58. Quijote, I, 34.

59. Sobre esto vid. Isabel Colón Calderón, «El linaje de Fabio», eHumanista: Journal of Iberian Studies, $\mathrm{n}^{\circ}$ 3, 2003, pp. 91-104.

60. «Un entrecano se entregó a la brava / de dos mujeres, doble bovería: / la una, aún tres lustros no cumplía; la otra, de edad torpe ya pasaba. / Eran los varios pelos que ostentaba / en su cabeza singular porfía, / que la moza, los canos los raía, / y la vieja, los negros los quitaba. / Quedaba el hombre, cual pensar podemos, / cuando sus destrozadas plumas vuelan, / feo despojo de los dos extremos. / El cuento avisa que, si nos desvelan / mujeres, de ninguna nos fiemos, / que la vieja, o la moza, todas pelan.» (Op. cit., p. 127). 
siguiente-, se mantenía inalterada la mencionada dispositio de respuesta y envío, provocación y contestación o, simplemente, arrastre, descrita ya en las páginas anteriores.

\section{EUTRAPELIA Y PRODUCTO IMPRESO: EL JUEGO EDITORIAL}

La dispositio de la Baraja es de una originalidad única en el panorama editorial en que se inscribe y ha sido objeto de atención por distintos especialistas desde enfoques diversos. Así, el maestro Alvar cifró en la disposición simbólica del poemario sus claves interpretativas, bajo consignas que apuntaban a la moralidad del volumen ${ }^{61}$. Étienvre, por su parte, valoraba la singularidad de este libro refiriéndose a él como un "caso límite» ${ }^{62}$. Y más recientemente Fasquel ha notado el importante valor de la dispositio de la última parte del poemario, la de carácter burlesco, como elemento fundamental en la definición del tono «serijocoso» del libro ${ }^{63}$.

Creemos que a estos planteamientos podrían sumarse consideraciones adicionales sobre el sentido que este modo de conformar un poemario pudiera tener en su contexto editorial y socio-literario desde la perspectiva, ya apuntada, de la dispositio lúdica del volumen y sus múltiples implicaciones.

A este respecto parece conveniente resaltar, de inicio, el evidente problema de atribución categorial que suscita el Entretenimiento [...] baraja nueva, y que atańe, como es lógico, a las dimensiones del libro y de la baraja, pues lo cierto es que se concilian sobre la materialidad del volumen dos de los

61. Según Alvar «lo que es original en el poeta es la interpretación simbólica que da a los palos de su baraja, no a considerar el libro como baraja; originalidad que conviene a una ordenación de la poesía atendiendo a una escala de valores (oro = poemas religiosos), de simbología aceptada (espada = poemas heroicos), de creación metafórica (copas = versos amatorios, o líricos) o de simple metonimia (bastos = versos burlescos)» (op. cit., p. 30).

62. En palabras de Étienvre lo que «debe llamar nuestra atención es que un poeta se valga de los naipes como de unos símbolos para calificar sus propios versos y estructurar su propio libro de poemas. El motivo naipesco se aplica aquí a la misma poesía: es un caso ejemplar, y probablemente un caso límite, que pone de manifiesto la insospechada riqueza de dicho motivo" (Jean-Pierre Étienvre, Márgenes literarios del juego. Una poética del naipe siglos XVIXVIII, Londres, Támesis, 1990, p. 18).

63. De acuerdo con Fasquel «si l'on pouvait qualifier le ton de ces sections de jocoserio en s'appuyant sur les hypothèses avancées par Jean-Pierre Étienvre, peut-être conviendrait-il de considérer que la poésie burlesque de Francisco de la Torre y Sevil est serijocosa, terme bien documenté en cette fin de XVII ${ }^{e}$ siècle d'après le même critique» (Samuel Fasquel, "Inventio et dispositio dans la Baraxa nueva de versos de Francisco de la Torre y Sevil (1654)», Mélanges de la Casa de Velázquez, n 35.2, 2005, pp. 191-218, p. 208). 
principales exponentes del consumo impreso de la cultura áurea: el juego de naipes y el juego de ficción editorial o libro de entretenimiento.

Esta difícil atribución categorial obliga a considerar el volumen como un problema en sí mismo, más aún cuando se trata de una rara síntesis de eso que García Santo-Tomás ha denominado como «objetos cotidianos que se convierten en dioses del mercado" ${ }^{64}$. Y es que efectivamente las barajas de cartas tenían una grandísima presencia en la cultura del ocio de todas las esferas de la sociedad áurea, desde las más bajas hasta las más elevadas ${ }^{65}$; y el objeto libro, por su parte, no era menos conocido. Así pues, con el Entretenimiento, Torre y Sevil consigue la conjunción efectiva de dos objetos tan cotidianos como la baraja de cartas y el volumen impreso, pero les sobreañade la novedad de una dispositio editorial y una carga de poesía culta absolutamente inéditas.

Debe advertirse, no obstante, que esta experimentación con el objeto tiene implicaciones que van más allá de las propias dinámicas del mercado, pues aunando las dimensiones disímiles de lo naipesco y lo poético se ahonda implícitamente en las hondas relaciones del juego y la literatura. Desde esta perspectiva, el libro profundizaría en algunos de los aspectos formulados por las tesis clásicas de Huizinga (1972) e Ynduráin $(1974)^{66}$, ya que en la Baraja la literatura se hace presente tanto en su dimensión lúdica como también en su dimensión socioliteraria de redes de relaciones, de superación poética y académica, de novedad literaria y editorial. En suma, este volumen plantea una visión de la poesía como juego social e individual en el que el poeta-tahúr crea su propio contexto discursivo y lúdico, concretando sobre la materialidad del libro-baraja una red de ingeniosas referencias cotextuales e intertextuales que conforman un espacio nuevo y distinto para la difusión de la poesía culta.

En la creación de este espacio impreso tienen gran importancia los títulos de los poemas, que marcan el diálogo entre las composiciones, así como la intitulación general del volumen, que participa muy activamente en la generación de un contexto lúdico fácilmente perceptible. Además, en el poemario de Sevil es evidente la conexión del marbete intitulador con la designación genérica de la prosa de ficción como «libros de

64. Enrique García Santo-Tomás, «Barroco material / material barroco», en Enrique García Santo-Tomás (ed.), Materia crítica: formas de ocio y de consumo en la cultura áurea, Madrid-Frankfurt, Iberoamericana-Vervuert, 2009, pp. 11-31, p. 18.

65. Cf. Étienvre, op. cit.

66. Cf. Johan Huizinga, Homo Ludens [1938], Madrid, Alianza, 1972; y Francisco Ynduráin, "Para una función lúdica en el lenguaje», en AA. VV., Doce ensayos sobre el lenguaje, Madrid, Fundación Juan March, 1974, pp. 212-227. 
entretenimiento» ${ }^{67}$, y esta orientación interpretativa no pasaría inadvertida entre los compradores del volumen.

Pese a que el libro de poesía impresa ya había adoptado en su forma externa, disposición y materialización una naturaleza editorial propia para diferenciarse de géneros con más éxito como las novelas o las comedias $\operatorname{adocenadas}^{68}$, el poemario de Sevil va más allá en su experimentación, pues en este "caso límite» también se trata de innovar, en los planos material y conceptual, para entroncar con la semántica del juego de otros libros cuyos iniciales rótulos editoriales marcarían los contornos de una suerte de cronotopo lúdico ${ }^{69}$.

En el espacio inaugural -desde el punto de vista de la lírica culta impresaque ofrece Sevil se asumen como propiamente poéticas las marcas distintivas de los diferentes palos (o manjares) de las barajas al uso, práctica que gozaba ya de cierta codificación; se sanciona el juego de naipes como cauce para la ordenación de la poesía culta; y se cubre todo ello con el manto de un ingenio, una utilidad y un entretenimiento avalados por figuras señeras del entorno literario zaragozano.

Pareciera como si, en el ambiente urbano (y a ratos ocioso) de la Zaragoza de mediados del XVII ${ }^{70}$, el clásico debate entre la utilidad y el deleite se solventara, para el caso de la poesía lírica culta impresa, con un instrumento editorial de contornos ambiguos en varios sentidos: la baraja apela, inmediatamente, a una órbita de juego censurada por moralistas de toda índole; pero, a la vez, los naipes tenían una importante potencialidad didáctico-moral, como queda de manifiesto en las múltiples barajas a lo

67. Tal y como se definen, de modo paradigmático, en el donoso escrutinio: «porque no hacen ni harán el daño que los de caballerías han hecho, que son libros de entretenimiento sin perjuicio de tercero.» (Quijote, I, 4). La cursiva es nuestra.

68. Cf. Ignacio García Aguilar, Poesía y edición en el Siglo de Oro, Madrid, Calambur, 2009, pp. 189-250.

69. Por estos mismos ańos piénsese, por ejemplo, en obras como el Nuevo plato de varios manjares para divertir el ocio (1658) de Luis Antonio, y que imprimió Juan de Ibar; o en la Noche de invierno. Conversación sin naypes (1662), cuyo autor no era otro sino el director de la Academia Literaria de Madrid. Se trata, además, de un libro en el que se relacionan, aunque antagónicamente, los naipes y el espacio de lo académico a través de la conversación que se refiere en el título. Y destacamos este marbete porque, de acuerdo con Étienvre, «menudeaban, para cuantos no querían mezclarse con la plebe, esas casas que por eufemismo se llamaban "de conversación" y a las cuales acudían los nobles [...]” (op. cit., p. 167). El mismo año de 1654, el impresor del Entretenimiento, Juan de Ibar, saca de sus planchas las Navidades de Zaragoza, repartidas en cuatro noches, de Matías Aguirre del Pozo.

70. Este ingenioso juego conceptual y editorial no puede desvincularse de la grata acogida hacia el impreso que estaba floreciendo en la Zaragoza de mediados del XVII. Sobre esto vid. el artículo de Pedro Ruiz Pérez en este mismo volumen. 
divino, algunas incluso para los reyes ${ }^{71}$, que se hicieron en la época. Justo esa capacidad formativa y sus valores positivos son los que permitirían conectar a la baraja poemario con una dimensión de la eutrapelia en la que se actualizan los valores del docere y el delectare.

Los límites de la licitud y moralidad del juego están determinados desde muy antiguo por el concepto de la eutrapelia aristotélica ${ }^{72}$, que actualizaría Santo Tomás con su comentario a la Etica ${ }^{73}$. Sin embargo, la interpretación de este concepto va evolucionando a lo largo del tiempo, de modo que desde la filosofía medieval se aplica progresivamente al comportamiento humano para referirse a la agilidad, la destreza física, la mutabilidad, la inconstancia; y más tarde se aplica al habla y la cortesanía, «sugiriendo la presteza del diálogo, los rasgos de ingenio, la llamada agudeza del Siglo de Oro español», de acuerdo con Wardropper ${ }^{74}$.

A la altura del siglo XVII el concepto presentaba una semántica difusa y ambigua, y su espectro significativo contaminaba muchas otras parcelas de lo lúdico en el seno de una sociedad cada vez más interesada por el ocio. Basta atender únicamente a las traducciones y definiciones del concepto de eutrapelia para comprobarlo.

Así, en un libro científico de tanta repercusión como la Nueva filosofía de la naturaleza del hombre, impreso en 1587 y reimpreso en $1622^{75}$, no se albergaba duda alguna sobre el sentido de la eutrapelia al afirmar que «las cosas que incitan y mueven el amor en el hombre y son amables son estas: sapiencia, semejanza, la eutrapelia (que es buena conversación), música» ${ }^{76}$.

71. San Francisco de Borja había creado en 1553 una baraja de carácter piadoso para Juana de Austria, por su desmedida afición a los juegos de naipes (cf. Étienvre, op. cit., pp. 57-61).

72. Aristóteles entendía la eutrapelia como la virtud del justo medio entre las bromas y los juegos. Pero el problema, claro está, estriba en definir dónde está el justo medio, y Aristóteles lo encuentra en la conducta del eutrapelos, esto es, el hombre que gira bien, el bene vertens. De acuerdo con el estagirita, en los escalafones de la sociabilidad el eutrapelos se ubica a medio camino entre los extremos del bomolochos (o bufón) y el agraikos (o triste). Los eutrapeloi evitan ambos extremos y son quienes usan las bromas y juegos de un modo virtuoso.

73. Ética IV, I. 16. Santo Tomás también indaga en esta virtud en la Summa Theologiae (II-II, q. 168, aa. 2-4).

74. Bruce Wardropper, «La eutrapelia en las novelas ejemplares de Cervantes», Giuseppe Bellini (ed.), Actas del Séptimo Congreso de la Asociación Internacional de Hispanistas, Roma, Bulzoni, 1982, pp. 153-169, p. 153.

75. La primera edición de 1587 se atribuye a Oliva Sabuco, aunque en la de 1622, que manejamos, aparece bajo el nombre de su padre, Miguel Sabuco. La autoría de la obra es, en todo caso, un asunto controvertido que ha generado bastante bibliografía crítica tanto en uno como en otro sentido.

76. Miguel Sabuco, Nueva filosofia de la naturaleza del hombre, no conocida ni alcanzada de los grandes filósofos antiguos, la cual mejora la vida y salud humana [...] compuesta por Doña 
Los vínculos de la eutrapelia con el plano lingüístico y el sentido de la sociabilidad que denota el concepto «buena conversación» se mantienen idénticos en obras morales de grandísima repercusión como, por ejemplo, las diferentes traducciones españolas de la Introducción a la vida devota de Francisco de $\mathrm{Sales}^{77}$, pues como «buena conversación» traducen el término eutrapelia tanto Francisco de Quevedo en $1634^{78}$, como Francisco Cubillas en $1663^{79}$.

Sin embargo, en otros tratados se apela a dimensiones que van más allá de la conversación. Es el caso de Arellano, quien afirma en la República cristiana (1662) que «eutrapelia es voz griega, que corresponde en castellano propiamente a la palabra destreza, y menos propiamente a urbanidad y cortesania ${ }^{80}$. Una valoración bien distinta ofrecía Cosme Gómez Tejada en El filósofo. Ocupación de nobles y discretos contra la cortesana ociosidad (1650), quien explicaba que las "partes potenciales de la templanza son ocho: continencia, mansedumbre, clemencia, modestia, humildad, estudiosidad, eutrapelia», y añadía que "la última tiene estos cuatro nombres: parcidad, parsimonia, simplicidad, moderación ${ }^{81}$; para concluir después que «eutrapelia, urbanidad o entretenimiento, es virtud que

Oliva Sabuco, Braga, Fructuoso Lourenzo de Basto, 1622 [1587], ff. 45r-45v. La cursiva es nuestra.

77. La primera edición de La Introducción a la vida devota se publica en francés en 1608, y casi de inmediato obtiene un gran éxito editorial, lo que propicia reimpresiones y traducciones a diversos idiomas. La primera edición en castellano data de 1618, pero un año después el autor completó el libro añadiendo diversos capítulos, apenas dos años antes de su fallecimiento.

78. "Cuanto a los juegos de palabras que se hacen los unos con los otros con modestia, regocijo y alegría, éstos pertenecen a la virtud llamada de los griegos eutrapelia, que nosotros podemos llamar buena conversación.» (Francisco de Quevedo, Introducción a la vida devota de san Francisco de Sales, Madrid, Ediciones Palabra, 2002, p. 274). La traducción quevedesca del obispo de Ginebra -traducida ya al latín (1614), espańol (1618), alemán (1618), italiano (1621) e inglés (1631) - fue, según Jauralde «una jugada maestra de propaganda editorial» (Francisco de Quevedo (1580-1645), Madrid, Castalia, 1999, p. 668).

79. «[...] los juegos de palabras, que se hacen de unos a otros con modestia, regocijo y alegría pertenecen a la virtud llamada eutrapelia por los griegos, y nosotros la podemos llamar buena conversación» (Introducción a la vida devota que en francés escribió el glorioso señor San Francisco de Sales [...], y tradujo, enmendó y añadió el Lic. D. Francisco Cubillas Don Yague [...], Madrid, Diego Díaz de la Carrera, 1663, p. 167).

80. Juan Remírez [sic] de Arellano, República cristiana y destierro de los vicios. Razón de estado y politica de la virtud. La eterna salvación, Madrid, Domingo García Morras, 1662, f. 130r. La cursiva es nuestra.

81. Cosme Gómez Tejada de los Reyes, El filósofo. Ocupación de nobles y discretos contra la cortesana ociosidad, Talavera de la Reina, Francisco Gómez Tejada de los Reyes, 1650, f. 91v. La cursiva es nuestra. 
pone modo conveniente en los juegos y burlas honestas que para relajar y recrear el ánimo tal vez no desdicen del varón más severo» ${ }^{82}$. No carece de importancia al respecto que alguien que dio con cierto éxito sus novelas morales a las planchas ${ }^{83}$ indagara en estas cuestiones sobre el papel del juego y el entretenimiento en el contexto de una sociedad urbana (y ociosa), recogiendo un concepto cada vez más amplio de la eutrapelia, en donde cabían las dimensiones del entretenimiento y la cortesanía. En 1652 Antonio López de Vega traducía eutrapelia como "honesto entretenimiento» ${ }^{84}$ en el prólogo que escribió al duque de Alburquerque para dedicarle El perfecto señor.

Pero el concepto no sólo plantea problemas categoriales en su definición, sino fundamentalmente, y quizá esto sea más importante aún, en su ámbito de aplicación. Sirva como ejemplo el Manual de confesores (1625) de Villalobos, en el que se explica que «el juego, de su naturaleza, es lícito y pertenece a una virtud que se llama eutrapelia, y son más lícitos el de la pelota y otros semejantes» ${ }^{85}$. La distinción entre juegos resulta significativa porque mantiene una actitud mucho más tolerante frente a los naipes que otras obras de moralidad. En este sentido, en la Introducción a la vida devota (1663) se censuraban los juegos de dados y los de cartas por basarse en la

82. Ibid., f. 92r. La cursiva es nuestra.

83. Aunque El filósofo (1650) es una obra de carácter científico escrita originariamente en latín, lo cierto es que su autor se dedicó, fundamentalmente, a la escritura de novelas bizantinas cargadas de apólogos moralizantes. La que gozó de más éxito fue su León prodigioso (1634), reimpresa tres veces a lo largo del XVII (Madrid, 1663; Valencia, 1663; Madrid, 1670 y Sevilla, 1732). Es autor de otra novela, también alegórica, aunque de menos éxito (Entendimiento y verdad, Alcalá de Henares, 1673). Su hermano publicó póstumamente un compendio de sus loas, villancicos y autos sacramentales bajo el título de Noche buena (Madrid, 1661). Sobre este autor vid. Abraham Madroñal Durán, «Vida y obra del licenciado Cosme Gómez de Tejada y de los Reyes (1593-1648)», Revista de Filología Española, n 71 , 1991, pp. 287-316.

84. «Doyle a V. Exc. en que ejercitar muchas de sus virtudes, y así en la variedad de los discursos como en la de los versos, si la severidad de la Milicia no se desdeńa de lo cortesano, podrá ser que halle su ingenio algo en que divertirse, sin que en esto pueda el bien común argüirme de mal repúblico, pues no sólo en la cortedad de la lectura, mas mucho más en la capacidad de V. Exc. puede caber el entretenerse honestamente, sin embarazar ninguna de las atenciones mayores a que la monarquía de España está incesablemente debiendo tanto. En cosa tan pública, afectación fuera sin fruto cualquiera elogio que, o con más verbosidad o con más elocuencia, aquí se introdujera. Y bien saben, o deben saber, los más exactos censores que entra también la eutrapelia (que es el honesto entretenimiento) en el número de las virtudes morales [...]» (Antonio López de Vega, El perfecto señor. Sueño politico con otros varios discursos y últimas poesías varias, Madrid, Imprenta Real, 1652). La cursiva es nuestra.

85. Enrique de Villalobos, Manual de confesores, Salamanca, Diego Cussio, 1625, f. $181 \mathrm{r}$. 
suerte y no en la razón ${ }^{86}$. Sin embargo, Villalobos concede, frente a quienes afirmaban que las cartas eran exclusivamente una cuestión de azar, que podía haber en los naipes algo de arte: «En unos juegos vale mucho la naturaleza y arte, y poco la ventura, como en la ajedrez y pelota; en otros vale mucho la ventura y poco o nada el arte, como en los dados y el quince; en otros vale todo, como es en las tablas y algunos juegos de naipes ${ }^{87}$.

Está claro, entonces, que los confesores debían entender que los naipes no eran sólo cuestión de azar, sino que también la técnica y la destreza del ingenio participaban del juego. Análogamente, Nieremberg en su Manual de señores y principes (1641) recuerda, cuando explica la virtud de la modestia, que a «los entretenimientos y juegos» les «asiste otra virtud que llaman con su nombre griego eutrapelia, que es la virtud de un honesto entretenimiento» ${ }^{88}$. Y más adelante explica, en el capítulo De la urbanidad y entretenimiento, que "cuatro suertes pueden diferenciarse de juegos», a saber: "Unos de solo ingenio, como es el ajedrez y damas; otros de solo fortuna, como los dados y algunos de naipes; otros son mezclados de fortuna e ingenio, como las tablas, y en los naipes hay algunos destos; otros hay de destreza, como los trucos» ${ }^{89}$.

Igual que en Villalobos, existe una posibilidad de naipes con ingenio, aunque no se define ni explicita. Había, por tanto, campo abierto en este sentido para indagar e innovar por la vía de la hibridación.

Pedro de Guzmán en sus Bienes del honesto trabajo y daños de la ociosidad (1614) explica sin dudas que «los naipes son otro libro, aunque desencuadernado, adonde los ociosos también estudian. Ésta es su Biblia, donde se sacan sus figuras y puntos, y no de oración ${ }^{90}$. Y paradójicamente vincula el autor esta Biblia con ídolos, de modo que «el rey de oros es el

86. «Los juegos de los dados, de los naipes y otros semejantes, cuya ganancia depende principalmente de la suerte no solamente son recreaciones peligrosas, como las danzas, pero son simple y naturalmente malas y vituperables. Por esto están prohibidas. "¿Pero qué tan grande es el mal que en esto hay?» -me dirás. La ganancia en estos juegos no viene según la razón, sino conforme la suerte, la cual de ordinario cae a aquél que, ni por su industria ni habilidad merece cosa alguna, y en esto es ofendida la razón [...]” (Introducción, trad. Francisco Cubillas, op. cit., pp. 181-182). El texto se incluye en el capítulo 32 De los juegos prohibidos, el cual lleva una anotación impresa al margen del título en la que se explicita que «todo este capítulo falta en la primera traducción» (ibid., p. 181).

87. Op. cit., f. $181 \mathrm{r}$.

88. Juan Eusebio Nieremberg, Obras y días. Manual de señores y principes en que se propone, con su pureza y rigor, la especulación y ejecución política, económica y particular de todas virtudes, Madrid, María de Quiñones, a costa de Francisco de Robles, 1641, p. 124.

89.Ibid., p. 128.

90. Pedro de Guzmán, Bienes del honesto trabajo y daños de la ociosidad, Madrid, Imprenta Real, 1614, p. 396. 
ídolo de Plutón, dios del oro y riquezas, y así él y ellas están debajo de la tierra y cerca del infierno»" ${ }^{91}$; el rey de bastos es «el ídolo de Saturno anciano y viejo y arrimado a un bastón» ${ }^{92}$; el de copas es "el ídolo de Baco», en tanto que «no falta quien al rey de espadas aplica el ídolo de Marte guerrero y furioso, causa de homicidios por causa deste juego" ${ }^{93}$. Sin duda, estos naipes librescos y su jerarquía temático-simbólica participan de un horizonte conceptual que no parece diferir en lo esencial de la Baraja de Torre y Sevil, en donde no existe nada reprochable desde el punto de vista moral. Y es que, de acuerdo con lo expuesto por Arellano en la República cristiana, "el libro, tal vez de provechosa erudición, cabe en la virtud de la eutrapelia» ${ }^{94}$.

Eutrapelia y libro, por tanto, pueden compartir una esfera común, aunque el amplísimo alcance de sus respectivos espectros conceptuales obligaba a definir sus límites. En todo caso, y pese a opiniones adversas, lo cierto es que los naipes quedan situados, en muchas de estas obras morales, en una posición elevada dentro de las posibilidades lúdicas, o al menos no totalmente denostadas. Un ejemplo muy ilustrativo de ello se recoge en los ya citados Bienes del honesto trabajo y daños de la ociosidad (1614), de Pedro de Guzmán. Así, y de acuerdo con el autor, parece que cuando Platón daba un descanso del estudio a sus discípulos y les pedía que gastasen «este tiempo ocioso en algún honesto ejercicio», los «muchachos con sus nueces juegan a pares y nones, los mozos a los dados, los viejos a los naipes»" ${ }^{95}$; igual que hacía León X, quien «jugaba con los cardenales un rato a los naipes», aunque "por recreación y nunca por ganancia» ${ }^{96}$.

Los vínculos entre naipes, libros, poemas, ocio y eutrapelia, en un campo abierto y por definir, parecen evidentes. Y será justo de esa indefinición de la que se valga el Entretenimiento [...] Baraja para formular su propuesta.

La Baraja de Torre y Sevil, desde luego, es un producto editorial nada común, y no se puede decir que tuviera descendencia; pero el intento por conjugar lo popular del juego y el impreso con lo más culto del ingenio poético, valiéndose para ello de un modelo dispositivo innovador y rupturista merece que se considere el proyecto con especial atención. Sobre todo porque supone una conciliación de las esferas del juego en su vertiente lúdica y jocosa, especialmente perceptible en el manjar cuarto.

91. Ibid., p. 399.

92. Ibid., p. 399.

93. Ibid., p. 398.

94. Op. cit., f. $135 \mathrm{v}$.

95. Op. cit., p. 423.

96. Ibid., p. 420. 
Atendiendo a esto merece la pena indagar algo más en el ya aludido anteriormente «deseo de entretener», que se esgrime como argumento para justificar las Poesías varias dedicadas a Torre y Sevil, y, por supuesto, el volumen que este dedicatario imprimió semanas después, en donde es el entretenimiento propio lo que justifica la escritura. Así, en la primera redondilla que dirige Al lector Torre y Sevil es harto explícito: «Lector, yo te ofrezco aquí / de mis vanas Musas frías / lo poco que algunos días / se entretuvieron en mí. / No quisiera en mal contento / rabiosa mordaz costumbre / que fuera tu pesadumbre / lo que es mi entretenimiento» ${ }^{97}$.

Conviene considerar que el «entretenido» es el que se divierte ocioso o el que dilata o suspende en el tiempo alguna operación, pero también, según Covarrubias, quien espera que se le haga alguna «merced o cargo». Y en sentido análogo, el «entretenimiento», según Autoridades, no sólo es la diversión o la dilación de alguna cosa, sino también la «ayuda de costa, sueldo y merced pecuniaria que se da para ayuda de mantenerse al que ha servido $\mathrm{u}$ al que se le ha esperanzado de conferirle algún empleo u ejercicio, y acomodarle».

El contexto naipesco no parece ofrecer dudas, en principio, sobre los valores lúdicos y ociosos del término. Sin embargo, los continuos juegos conceptuales que entreteje Sevil, basados en el valor anfibológico de los términos empleados, permiten también engarzar todo esto con lo estrictamente pecuniario, máxime cuando se trata de un objeto destinado al mercado. Así, en las mismas redondillas le pide Al lector, refiriéndose a la Baraja: "Ábrela, aunque quedes harto / al instante de leella, / no pierdas horas con ella / ni doblones, sino un cuarto» ${ }^{98}$.

Sea como fuere, lo cierto es que el «entretenimiento»-en su dimensión ociosa y lúdica, pero acaso también dineraria y de medro académico o literario- es el concepto fundamental que se esgrime para justificar el poemario de Sevil, al igual que el de Alfay. Aunque ciertamente no era la justificación prototípica para la impresión de poesía culta profana. Se solía más bien apelar a lo ingenioso de lo antologado, a la deuda contraída con un dedicatario o un poeta fallecido, a lo útil que podría resultar para la patria o la república de los poetas, o simplemente para que no se perdiesen los escritos valiosos.

Pero, insistimos en esto, la edición de poesía lírica culta justificada por un simple ejercicio de "entretenimiento» no era en absoluto común para este género. No lo hizo Espinosa, quien sí que apeló al duque de Béjar y a la

97. Op. cit., p. 92, vv. 1-8. La cursiva es nuestra.

98. Ibid., p. 93, vv. 49-52. 
variedad y novedad del volumen, pero no a sus cualidades como divertimento. Ni tampoco lo hizo el máximo representante del entretenimiento masivo en los corrales y paradigma de la profesionalización editorial del poeta: nunca Lope de Vega apeló al entretenimiento para justificar la impresión de su poesía.

Y si se refieren los vínculos que tienen con la dimensión del entretenimiento tanto la Baraja como las Poesías varias es porque estas recopilaciones de lo múltiple y lo individual comparten presupuestos muy similares en lo que atańe al papel del ingenio, de la varietas y de los promotores poéticos que se concitan en ambos libros, pero sobre todo, del entretenimiento vinculado a la impresión de lírica culta. Conviene advertir, sin embargo, que es éste un «entretenimiento» acotado que no se justifica a cualquier precio, pues, como precisa Torre y Sevil al final de sus redondillas Al lector, «si al necio le dan espantos / estos entrincados modos, / yo no escribo para todos, / porque no juego con tantos» ${ }^{99}$.

Este planteamiento puede ofrecer indicios suficientes para entender que el mismo Gracián que abominaba en el Criticón del «entretenimiento» masivo y sin orden fuera un defensor acérrimo del Entretenimiento selectivo y ordenado de la Baraja de Torre y Sevil.

\section{CONCLUSIONES: POEsía Y BARAJA}

En un trabajo reciente titulado "Poesía y farmakós en la edición de Vaca de Alfaro (1666)» ${ }^{100}$, Pedro Ruiz analiza la Lira de Melpómene como indicio de la conciencia y formulación de la doble naturaleza poética en el ecuador del siglo XVII, e indaga en las estrategias que permiten a Vaca de Alfaro ofrecer su poesía y su imagen de poeta en clave de farmakós; esto es, en tanto que veneno y triaca que tiene su concreción última en el propio poemario impreso, planteando una idea de catarsis que se podría vincular con la eutrapelia como liberación del poemario de Sevil. En cierto modo, la Baraja de Torre y Sevil opera mediante un proceso de transmutación

99. Ibid., p. 95, vv. 101-104. Sin duda hacía bien Alfay en restringir el ámbito de recepción de su baraja, pues ya Quevedo había aclarado que «libro que es para todos guárdele, que el autor, sea quien fuere, confiesa que es obra vulgar y bazofia» (Francisco de Quevedo, La Perinola, en Obras festivas, ed. Pablo Jauralde, Madrid, Castalia, 1987, p. 175). No se pueden pasar por alto, en este sentido, las consideraciones hechas por Anne Cayuela sobre la selección de un lector ideal en su epígrafe Les jeux titulaires: du Para todos au Para sí, en Le paratexte au Siècle d'Or, Genève, Droz, 1996, pp. 126-128.

100. En prensa. 
similar fundado en una noción muy abierta de eutrapelia y amparado por la aceptación generalizada hacia los naipes.

El vínculo de la eutrapelia con la poesía no es, desde luego, algo privativo de Torre y Sevil, aunque sea él quien lleve este juego hasta una concreción editorial evidente. Baste recordar al respecto cómo Cascales en sus Cartas philologicas (1634) vincula la eutrapelia gongorina al entretenimiento ${ }^{101}$ o cómo en el Segundo volumen de las obras de Soror Juana Inés de la Cruz (1692) la censura de Cristóbal Bañes de Salcedo alude directamente a la «discretísima eutropelia en las poesías» ${ }^{102}$ para validar el libro.

La permeabilidad inherente a las categorías del juego y la literatura alcanza una dimensión mayor en el Entretenimiento, al concretar sobre el soporte impreso una plasmación del espacio lúdico naipesco, el cual gozaba de una amplísima aceptación popular. El poemario-baraja acoge, probablemente, los tres principales elementos propios del juego, esto es, la jocosidad (iocus), el uso de normas y transgresiones (vinculado al problema de la eutrapelia poética) y, por supuesto, la práctica lúdica, vinculada al ingenio.

Como ha señalado Ruiz Pérez, el espacio lúdico «domina una vertiente significativa, la más literaria (en sentido moderno), de Cervantes a Góngora, ejemplo de tahúr, maestro de la parodia y de lo puramente jocoso», $\mathrm{y}$ ańade que es precisamente en los contornos de este espacio lúdico en «donde se producen las mayores y más trascendentes innovaciones del período» ${ }^{103}$.

Pues bien, conforme a esto, Torre y Sevil elaboró un producto basado en un Entretenimiento polisémico que apelaba al ocio, pero también al

101. «A fe de hombre de bien que me parece que el archipoeta de Córdoba (quem honoris gratia nomino), ha querido representar estos días al sacristán de Paulenca, teniendo con su buen capricho a los más poetas de Espańa descaperuzados, aguardando que dé la tercera campanada. No digo yo que este humor es natural en él, sino que ha sido eutrapelia y rato de entretenimiento, arrojando la capa capitular por el ameno prado, para desenfadarse del continuo coro, gustando de dar papilla a los demás poetas con esta nueva secta de poesía ciega, enigmática y confusa, engendrada en mal punto y nacida en cuarta luna.» (Década primera. Epistola VIII. Al licenciado Luis Tribaldo de Toledo, en Francisco Cascales, Cartas philologicas [Murcia, Luis Verós, 1634], Alicante, Biblioteca Virtual Miguel de Cervantes, 2005, pp. 76-77). La cursiva es nuestra.

102. «[...] centelleen sus poemas, tropos, figuras, alusiones, metáforas, exacta mitología, exquisita elección de palabras, hermosa variedad de sentencias, distribución judiciosa, discretísima eutropelia en las poesías dirigidas a tantas personas príncipes, por cuya suavísima consonancia pudo oír con más razón que otro lo que de Nepotiano dijo Ausonio: Te fabulantem non Vlixes linqueret, / liquit canentes, qui melodas virgines.» (Censura de don Cristóbal Bañes de Salcedo, en Segundo volumen de las obras de Soror Juana Inés de la Cruz, Sevilla, Tomás López de Haro, 1692).

103. Pedro Ruiz Pérez, "Días lúdicos: juego, ocio y literatura», en Enrique García SantoTomás (ed.), op. cit., pp. 35-58, p. 55. 
negocio y al medro, avalado todo esto por las imágenes parnasianas que eran sobradamente conocidas y utilizadas en los entornos poéticos. Por otro lado, la Baraja nueva apela a referentes de innovación muy evidentes, que van desde el horizonte de arrastre y superación que sugiere el juego de cartas hasta lo popular paremiológico: piénsese en el refrán «A cuentas viejas, barajas nuevas», es decir, "cuando las cuentas y negocios están muy embrollados, es preciso tomar un nuevo partido».

Acaso algo de esto ocurría en el panorama poético y editorial del momento; y la muestra o baza jugada por Sevil fue perfectamente seguida por quienes, como Ana Francisca de Abarca de Bolea, alababan la innovación del libro, al afirmar en su poema preliminar: «se os ha entendido la flor [engaño, marca del tahúr] / con que de mano ganáis [adelantarse en novedad]» ${ }^{104}$. Y en lo mismo insiste Ana María de Zayas, cuando subraya «que después de hacer la mano, [jugar el primero, el que arrastra] / os hacéis con la Baraja» ${ }^{105}$. Siendo, por tanto, Torre y Sevil el que asistía, y recurriendo a esta misma imagen, advertía él mismo a su lector: «Por nueva la discurrí, / no servida en tal partida, [un palo nuevo, muestra para seguir] / mas ya se da por servida, / si acierta a servirte a ti / [...] / Mas si en otros juegos entro [no sigue envite, cambia de palo] / desquite, oh noble lector, / al azar de tanto error / de algún acierto el encuentro» ${ }^{106}$.

Y ejecuta Sevil este cambio de palo de un modo inusitadamente original, ofreciendo un modelo (la baraja y sus manjares), comúnmente reconocible en sus contornos externos, en el que dar rienda suelta a toda la variedad poemática; ofrece, en fin, patrones de una cierta homogeneidad genérica en sentido editorial, así como un envío o reto a jugar con tal baraja. Y hace esto para un producto de autor único, al mismo tiempo que sale al mercado un volumen editorial, también innovador, como son las Poesías varias, con las concomitancias entre ambos ya señaladas. Se podría argüir que la relación Alfay-Gracián-Sevil es clara, pero que disuena la intervención del impresor de la Baraja Juan de Ibar. No obstante, conviene recordar que, poco tiempo después de esto, de la colaboración entre Alfay y Juan de Ibar sale también en las prensas zaragozanas el Bureo de las musas, volumen en que la eutrapelia poética ya apuntada anteriormente se asocia con un género más abiertamente vinculado al entretenimiento, como es la novela. Y el propio Ibar sacó de sus talleres en el mismo 1654 las Navidades de Zaragoza, repartidas en cuatro noches, de Matías Aguirre del Pozo, volumen

104. Op. cit., p. 83, vv. 3-4. La cursiva es nuestra.

105. Ibid., p. 84, vv. 9-10. La cursiva es nuestra.

106. Ibid., p. 93, vv. 25-28 y 41-44. 
heterogéneo, fundamentalmente novelístico, basado también, como la baraja, en una estructuración cuatripartita.

El juego de cartas, igual que el poético, conlleva un sentido de competición y superación que en el caso del Entretenimiento se explicita en algunos de sus poemas preliminares. Además, el signo de la competición y el juego, relacionado con la poesía, fácilmente permite vincular estas prácticas poéticas con el entorno de academias y de justas ${ }^{107}$, de tanta importancia en Zaragoza $^{108}$.

La estampación de un juego poético de esta naturaleza supone una visualización evidente del poeta y de su propuesta lúdica, pero también del grupo de autores del que formaba parte, muchos de los cuales validan tan peculiar baraja en los preliminares del libro. Y acaso ésta era la estrategia conjunta de las Poesías varias y del Entretenimiento: la visualización de un entorno poético que asociaba sus prácticas a lo lúdico del juego, en su dimensión jocosa e ingeniosa, y que entendía que sólo por la vía de la sorpresa y del alarde intelectual se podía obtener entretenimiento y diversión. Pero lo abrían, además, al espacio público del consumo, valiéndose entonces del reclamo de algo tan conocido como los naipes. La opción por proyectarse de esta manera tan amplia y de vincular el resultado del ingenio al mercado implica una equiparación implícita del producto poemario lírico impreso con otros objetos editoriales, como la novela o el teatro, que apelan sin género de dudas a un público necesariamente ocioso y mayoritariamente urbano, con los problemas inevitables que conllevan estas prácticas. Sin embargo,

107. No era éste, por otra parte, un entorno desconocido para el poeta, pues parece que además del entorno zaragozano formó parte de la Academia del Conde Lemos (cf. Aurora Egido, La poesía aragonesa del siglo XVII y el culteranismo, Barcelona, 1976, p. 15) y participó, asimismo, en diversas justas poéticas levantinas (Alvar, op. cit., p. 3; Querol Coll, op. cit., pp. 262-269). Y sería justamente en Valencia en donde se imprimieran las Varias hermosas flores del Parnaso (1680), volumen muy indicativo de la grata acogida dispensada a la poesía de Torre y Sevil en tierras levantinas.

108. Vid. Ricardo del Arco y Garay, La erudición aragonesa en el siglo XVII en torno a Lastanosa, Madrid, Cuerpo Facultativo de Archiveros, Bibliotecarios y Arqueólogos, 1943 y La erudición española en el siglo XVII y el cronista de Aragón Andrés de Ustarroz, Madrid, CSIC, 1950; José María Castro y Calvo, Justas poéticas aragonesas del siglo XVII, Zaragoza, Universidad de Zaragoza, 1937; José Manuel Blecua, «Papeletas literarias en manuscritos aragoneses», Universidad. Revista de cultura y vida universitaria, no 19.2, 1942, pp. 43-69; Aurora Egido, "Los modelos en las justas aragonesas del siglo XVII», Revista de Filología Española, no 55, 1979, pp. 159-171 y "Certámentes poéticos y arte efímero en la Universidad de Zaragoza (siglos XVI y XVII)», en Aurora Egido et alii (ed.), Cinco estudios humanísticos para la Universidad de Zaragoza en su IV centenario, Zaragoza, Caja de Ahorros de la Inmaculada, 1983, pp. 9-73. 
y como precisaba Sevil en los versos citados anteriormente, el juego no era para todos.

Tanto en la novela como en el teatro la ficción es el juego que se ofrece al público y que éste aceptará para su deleite. En el caso del Entretenimiento de las musas, el juego es el propio volumen, reconocible por todos en virtud del «trueque» entre «libro»y «baraja»; y ni siquiera es ya necesario apelar a una ocasión de importancia o remedar la ficcionalización de un conflicto que justifique la escritura y la posterior estampación de los poemas. Probablemente, nunca hasta entonces un poemario de lírica culta impresa tocó al mercado del ocio tan de cerca.

Pareciera como si vientos de cambio hubiesen aireado Zaragoza en el verano de 1654, en el intento por conformar un modelo editorial que diera salida a la poesía lírica, tanto de autor único como de autor múltiple.

Torre y Sevil, como Alfay, iba de mano, con un palo distinto y una baraja nueva; arrastró, pero no le asistieron en el juego. 